Article

\title{
Performance Results of a Solar Adsorption Cooling and Heating Unit
}

\author{
Tryfon C. Roumpedakis ${ }^{1}{ }^{\mathbb{D}}$, Salvatore Vasta ${ }^{2, *} \mathbb{1}$, Alessio Sapienza ${ }^{2}$, George Kallis ${ }^{1}$, \\ Sotirios Karellas ${ }^{1}$, Ursula Wittstadt ${ }^{3}$, Mirko Tanne ${ }^{3}$, Niels Harborth ${ }^{4}$ and Uwe Sonnenfeld ${ }^{4}$ \\ 1 Laboratory of Steam Boilers and Thermal Plants, School of Mechanical Engineering, National Technical \\ University of Athens, 15780 Athens, Greece; troumpedak@central.ntua.gr (T.C.R.); \\ gkallis07@mail.ntua.gr (G.K.); sotokar@mail.ntua.gr (S.K.) \\ 2 Consiglio Nazionale delle Ricerche (CNR), Istituto di Tecnologie Avanzate per l'Energia “Nicola \\ Giordano" (ITAE), 98126 Messina, Italy; alessio.sapienza@itae.cnr.it \\ 3 Fahrenheit GmbH, 80803 Munich, Germany; ursula.wittstadt@fahrenheit.cool (U.W.); \\ mirko.tanne@fahrenheit.cool (M.T.) \\ 4 AkoTec Produktionsgesellschaft mbH, 16278 Angermünde, Germany; niels.harborth@akotec.eu (N.H.); \\ uwe.sonnenfeld@akotec.eu (U.S.) \\ * Correspondence: salvatore.vasta@itae.cnr.it; Tel.: +39-090-624404
}

Received: 23 February 2020; Accepted: 19 March 2020; Published: 2 April 2020

\begin{abstract}
The high environmental impact of conventional methods of cooling and heating increased the need for renewable energy deployment for covering thermal loads. Toward that direction, the proposed system aims at offering an efficient solar powered alternative, coupling a zeolite-water adsorption chiller with a conventional vapor compression cycle. The system is designed to operate under intermittent heat supply of low-temperature solar thermal energy $\left(<90{ }^{\circ} \mathrm{C}\right)$ provided by evacuated tube collectors. A prototype was developed and tested in cooling mode operation. The results from the testing of separate components showed that the adsorption chiller was operating efficiently, achieving a maximum coefficient of performance (COP) of 0.65. With respect to the combined performance of the system, evaluated on a typical week of summer in Athens, the maximum reported COP was approximately 0.575 , mainly due to the lower driving temperatures with a range of $75^{\circ} \mathrm{C}$. The corresponding mean energy efficiency ratio (EER) obtained was 5.8.
\end{abstract}

Keywords: solar cooling; adsorption; evacuated tube collectors; experimental testing

\section{Introduction}

Renewable energy sources gained significant interest over recent years owing to the depletion of fossil fuel reserves and the growing concerns over the environmental impact of conventional cooling and heating technologies. Moreover, the European Union sub-target of increasing the renewable heating and cooling by $1.3 \%$ per year, starting in 2021, outlines the necessity for more sustainable solutions in the field [1]. Taking into consideration the concurrence between the solar availability and the peak building demands, solar energy could be one of the most reliable, commercially mature alternatives toward the minimization of the heating and cooling sector environmental footprint [2].

With respect to solar-driven heating/cooling, there are two main technologies: photovoltaic (PV)-driven reversible heat pumps and solar thermally driven sorption heat pumps [3,4]. Currently, the PV-driven cooling/heating systems dominate the market, thanks to the overall growth of the PV market, which is expected to gain a share of $16 \%$ of the total energy production by 2050 , according to the International Energy Agency [5]. This expansion of the PV market, along with the respective increased use of reversible heat pumps, resulted in low specific capital costs for the PV-driven cooling/heating systems, making this technology the most competitive solar-driven cooling/heating technology [6]. 
On the other hand, the majority of commercially available solar thermally driven cooling/heating set-ups implement an absorption heat pump, mainly due to the fact that absorption is the most mature thermally driven cooling/heating technology [7], as well as owing to the higher involved coefficient of performance (COP, the ratio between the cold produced and the heat spent to produce it [8]) and the lower capital costs compared to the other sorption technologies [9]. Several solar absorption applications were developed and are currently in operation across the world. For instance, a solar-driven absorption system was installed at the Center for Renewable Energy Sources and Saving (CRES) in Pikermi, Athens, Greece, and it is in operation since December 2011. The solar field consists of flat plate collectors with a total surface of $149.5 \mathrm{~m}^{2}$, while an underground energy storage system with a total volume of $58 \mathrm{~m}^{3}$ is also installed. The $\mathrm{LiBr}-\mathrm{H}_{2} \mathrm{O}$ absorption chiller has a nominal capacity of $35 \mathrm{~kW}$, while an 18-kW conventional heat pump is installed as a backup. According to measurements conducted by Drosou et al. [10], the achieved solar fraction is around $70 \%$. The annual cooling demands were estimated to be $19.5 \mathrm{MWh} / \mathrm{a}$, which refers to the period of May-September, while the respective heating loads were 12.3 MWh/a for the period of October-April [11].

Adsorption technology gained attention over the past few years, thanks to its potential to exploit very low-grade heat sources, the absence of crystallization issues, and the simplicity of the involved equipment due to the absence of a solution pump and a rectifier [12,13]. Furthermore, compared to conventional electrically driven systems, the adsorption technology has advantages in the lower operating costs, the absence of moving parts, and the absence of vibrations [14]. On the other hand, a key drawback for adsorption technology is the relatively low COP [15].

Solar adsorption systems were already investigated thoroughly in terms of both their theoretical and their experimental performance [16,17].

In Reference [18], Rahman et al. introduced an innovative thermodynamic cycle based on a four-bed layout and three stages which can be powered by low-temperature heat. The mathematical simulations conducted showed that the maximum coefficient of performance of the system can be achieved for a regeneration temperature at $55{ }^{\circ} \mathrm{C}$, while the optimal cycle time was dependent on the corresponding heat source temperature, thus proving the possibility to employ an adsorption chiller for solar applications. Habib et al. [19] simulated the performance of a two-stage four-bed silica gel-water adsorption system, powered by evacuated tube collectors. For the needs of the simulations, the heat source temperature was varied from 40 to $95^{\circ} \mathrm{C}$. In single-stage mode (driving temperature of $80^{\circ} \mathrm{C}$, cooling water temperature of $30^{\circ} \mathrm{C}$, and chilled water inlet temperature $14^{\circ} \mathrm{C}$ ), the $\mathrm{COP}$ was around 0.48 . On the other hand, when the driving temperature was lower $\left(50^{\circ} \mathrm{C}\right)$, the system operated in two stage mode, with a COP of approximately 0.27. Lemmini and Errougani [20] tested a single-bed methanol-activated carbon (AC-35) adsorption unit powered by a flat plate collector. Several experiments were conducted, achieving a maximum solar COP between 0.05 and 0.08 and a minimum temperature of $-11^{\circ} \mathrm{C}$. Aristov et al. [21] evaluated simulations of their solar refrigeration system developed based on a closed adsorption cycle. Among several chemisorbents, $\mathrm{CaCl}_{2}$ in silica gel composite sorbent was found to be the most efficient sorbent for water adsorption, resulting in a cycle COP equal to $0.6-0.8\left(T_{e}=5{ }^{\circ} \mathrm{C}, T_{c}=35^{\circ} \mathrm{C}\right.$, and $\left.T_{d e s}=80^{\circ} \mathrm{C}\right)$ evaluated experimentally in a silica gel single-bed adsorption chiller driven by $4-\mathrm{m}^{2}$ evacuated tube collectors under the climatic conditions of Baghdad, Iraq. The nominal driving heat temperature was set at approximately $90^{\circ} \mathrm{C}$. Under varying experimental conditions, the optimal working point of the chiller was determined to be achieved at an evaporator temperature of $6.6^{\circ} \mathrm{C}$, which corresponded to a COP of 0.55. Chorowski et al. [22] investigated the performance effects of the control strategy on a three-bed, two-evaporator adsorption chiller. The authors demonstrated that changes to the control system can improve the performance of the chiller, especially in terms of COP. However, improvements were still limited; average COP was improved by $7.5 \%$ while the peak COP was improved by $11 \%$ up to 0.71 . Due to the aforementioned drawbacks of adsorption technology, there are fewer applications of solar adsorption cooling. One of the earliest solar thermal systems based on a $5.5-\mathrm{kW}$ adsorption chiller was developed 
and installed at the Institute for Solar Energy System (ISE) in Freiburg, Germany. The measurements conducted between August 2008 and July 2009 revealed an average COP of 0.43 [23].

In most theoretical and experimental investigations, the adsorption chillers used a silica gel-water working pair, mainly due to the stability and the low cost of silica gel. Lu et al. [24] analyzed the performance of a novel solar-driven adsorption air-conditioning system. The cooling capacity of the measured silica gel-water adsorption system was approximately $3.6 \mathrm{~kW}$, corresponding to a COP of $0.32\left(T_{e}=15^{\circ} \mathrm{C}, T_{\mathcal{C}}=27^{\circ} \mathrm{C}\right.$, and $\left.T_{d e s}=57^{\circ} \mathrm{C}\right)$. Koronaki et al. [25] simulated a two-bed silica gel-water adsorption chiller powered by various types of solar collectors. The system was evaluated for three cities in the southern Mediterranean region, namely, Athens (Greece), Nicosia (Cyprus), and Alexandria (Egypt). With respect to the adsorption module, the optimal type of solar collector was a selective flat plate one, resulting in a cooling COP of 0.51 . However, with respect to the exergy efficiency maximization, the optimal type of solar collector was the unglazed photovoltaic/thermal (PV/T) system with an overall efficiency of $11.35 \%$. Similarly, Alahmer et al. [26] assessed a two-bed silica gel-water adsorption chiller driven by concentrated solar collectors. At the peak hour, the estimated COP was around 0.5 , for a cooling output of $11 \mathrm{~kW}$. In terms of economics, the proposed system resulted in a payback period of 11 years, using a solar field of $38 \mathrm{~m}^{2}$.

A small number of solar adsorption installations are operating across Europe for air-conditioning applications. One of the first solar cooling installations was the set-up at the university hospital of Freiburg. The system, which was installed in 1999, is used to cover the cooling loads of a lab section with a total area of $550 \mathrm{~m}^{2}$. The adsorption chiller has a cooling capacity of $70 \mathrm{kWc}$, with a nominal COP of 0.6 , while the nominal output temperature of the chilled air is $9^{\circ} \mathrm{C}$. The system is powered by a $167 \mathrm{~m}^{2}$ vacuum tube collector field, while backup heating is supplied by the district heating network [23]. Another set-up of solar adsorption cooling is used in a cosmetics company (Sarantis S.A.) in Greece. Using a $2700 \mathrm{~m}^{2}$ field of flat plate collectors, two 350-kWc silica gel-water adsorption chillers are operated in order to air-condition a total space of 22,000 $\mathrm{m}^{2}$ [27]. Despite the attractiveness of the aforementioned solutions, the need to cover thermal loads in the absence of solar irradiance results in the use of conventional backup systems. In order to overcome this issue, recently, several hybrid adsorption/compression solutions were proposed [28,29]. Cyklis [30] investigated a two-stage cascade adsorption-compression system, consisting of a solar-driven commercial silica gel-water adsorption chiller and a low-temperature $\mathrm{CO}_{2}$ compression cycle. Compared to a conventional double-stage $\mathrm{CO}_{2} \mathrm{R} 410 \mathrm{~A}$ compression cycle, an energy saving up to $30 \%$ was estimated, while the respective percentage for total equivalent warming impact was as high as $60 \%$. Miyazaki et al. [31] evaluated two different configurations of hybrid adsorption/compression cycles, namely, the sub cooling type and the cascading type. The results of the simulations indicated that the cascading cycle enhanced the COP by $40 \%$, while the sub cooling configuration performed better in terms of system size and, thus, capital costs of the system. Palomba et al. [32] evaluated different configurations of cascade adsorption/compression chillers for various applications and discussed the key aspects in the proper sizing of the two sub-systems for maximization of the energy savings and overall system performance.

The ZEOSOL project [33] is based on the hybridization of an adsorption chiller with a conventional vapor compression cycle. The implementation of the vapor compression cycle allows covering the peak loads; hence, the adsorption chiller operates at higher COP, while, in the absence of solar irradiance, the conventional system is able to fully cover the loads of the residential building [34].

The system was designed with particular attention paid to the environmental impact of the developed system, compared to conventional alternatives, as presented by Kallis et al. [35]. The life-cycle assessment (LCA) of the investigated system, using the ReCiPe 2016 method, outlined the significant reduction in the system's impact on global warming and ozone depletion with respect to conventional reversible heat pumps. On the other hand, the worse performance of the system in impact factors such as the land use and the mineral resource scarcity highlighted the necessity for further optimization of the coupling toward the reduction of the excessive use of copper. 
In the present study, the authors investigate the preliminary experimental performance of a solar-driven hybrid cooling and heating system based on a small-scale zeolite-water adsorption chiller in adsorption only mode. The prototype system was designed to fully cover the thermal loads of a residential building with a $12.5-\mathrm{kW}$-peak cooling load.

\section{System Description}

The proposed system focuses on the coupling of a zeolite-water adsorption chiller with solar thermal collectors. The cooling capacity of the developed sorption chiller exceeds $10 \mathrm{~kW}$ using SAPO-34 as the adsorbent. To reduce the chiller's capacity and, thus, the required solar field area, while simultaneously enhancing the efficiency of part-load operation, a backup electrically driven heat pump is coupled with the adsorption chiller. The backup heat pump has a nominal cooling capacity of $10 \mathrm{~kW}$ and is used mainly to cover peak loads. The solar field consists of three rows of advanced evacuated tube collectors with a total surface of $40 \mathrm{~m}^{2}$. The system is also equipped with a $1-\mathrm{m}^{3}$ heat storage tank, which absorbs the spikes in solar energy, allowing for a more stable operation of the sorption module. A "V-shaped" dry cooler is implemented as the heat rejection unit for both the adsorption chiller and the backup heat pump, retrofitted for the specific application. An overview of the prototype, including the installed measuring devices, is shown in Figures 1 and 2, while images of the actual set-up are also provided in Figure 3.

To enhance the solar collector's performance and allow risk-free operation in low ambient temperatures, a propylene glycol solution is used as the working medium for the solar subsystem. Moreover, all secondary circuits of the adsorption chiller use pure water. The $1-\mathrm{m}^{3}$ heat storage tank is equipped with heat coils, via which heat is transferred from the glycol solution toward the hot water, which in turn drives the adsorption chiller. All temperature measurements were obtained using Pt1000 thermal sensors, class A according to DIN/EN 60751. The flow sensors used were ultrasonic in-line flow meters with a $2 \%$ accuracy. The electrical power consumption of the dry cooler, the compressor, and the circulation pumps was measured using energy analyzers. Finally, the solar radiation and the ambient conditions were monitored via a solar weather station, equipped with a second-class (as ISO 9060) pyranometer, a Pt1000 thermal sensor, an air humidity sensor, and an anemometer.

The experimental procedure focused on optimizing the coupling of the solar module with the hybrid adsorption-compression chiller. Therefore, several experiments were conducted, varying the target temperature of the storage tank ( $T_{s t, 3}$ in Figure 1$)$ and the high- and low-temperature setpoints of the chiller. The proper selection of a target temperature in the storage tank is of key importance for the operation of the system, in order to allow for maximum operation of the solar-driven system, while retaining sufficient high-temperature (HT) inlet temperatures for maximum efficiency of the adsorption chiller. In each day/experiment, the solar circuit started operation when the solar irradiance was over $200 \mathrm{~W} / \mathrm{m}^{2}$, charging the storage tank with the collected solar heat. When the HT setpoint temperature was reached at $T_{s t, 3}$ (see Figure 1 ), the pumps of the chiller were set on and the chiller initiated its start phase. The charging of the storage tank until $T_{s t, 3}$ reached the HT setpoint was a selection made by the user, as it was identified that it provided sufficient heat to operate the system for a prolonged period of time. The proper selection, on the other hand, of the HT and low-temperature (LT) setpoints was of key importance, as it is expected to have a direct influence on the system's COP and the duration of the system's solar-driven daily operation.

The system's cooling mode consists of three modes of operation, namely, adsorption-only operation which is driven solely by solar energy (Figure 2a), compression-only operation, and their combined operation (Figure 2b). This paper does not discuss the compression-only operation, as it is of no scientific interest, owing to its maturity. 


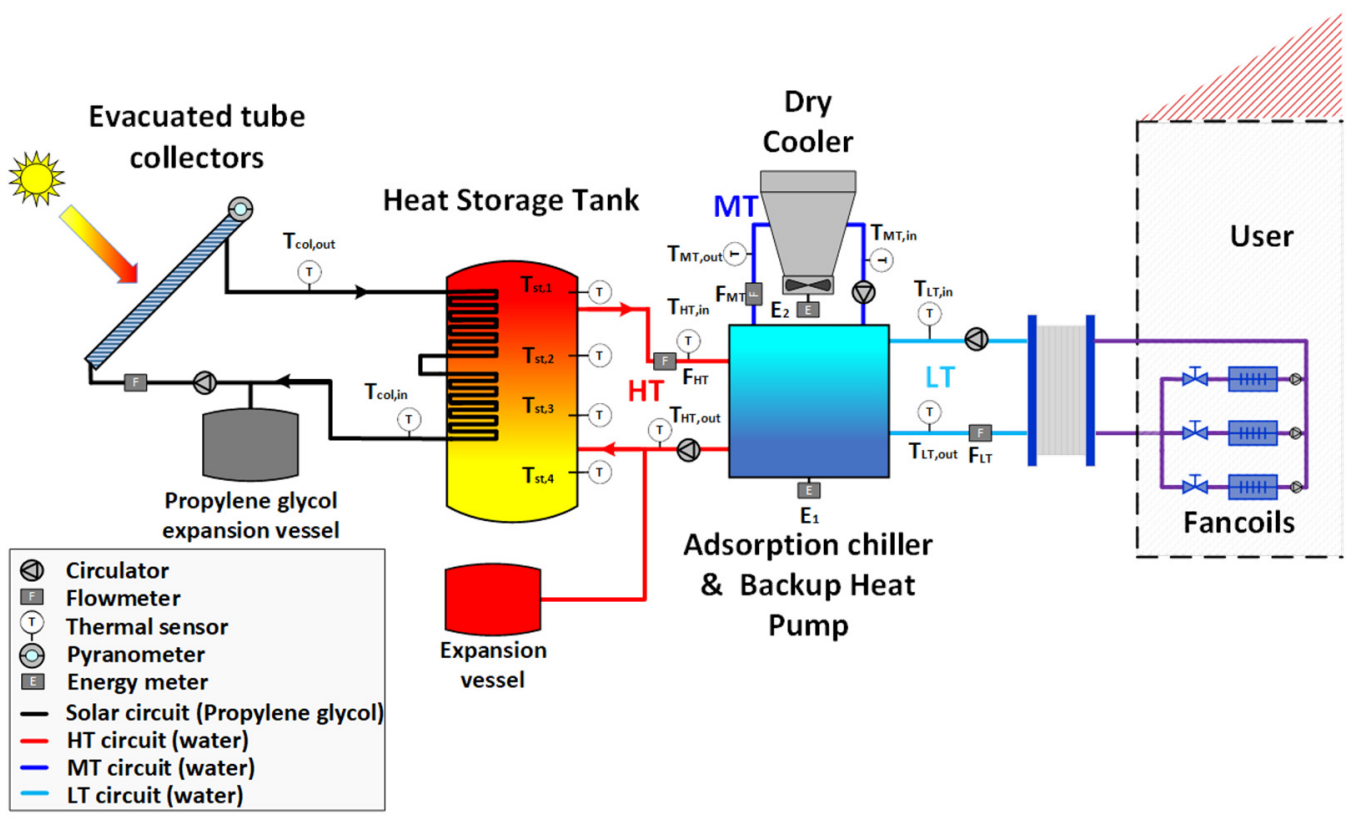

Figure 1. Schematic of system prototype with all the involved measuring devices.

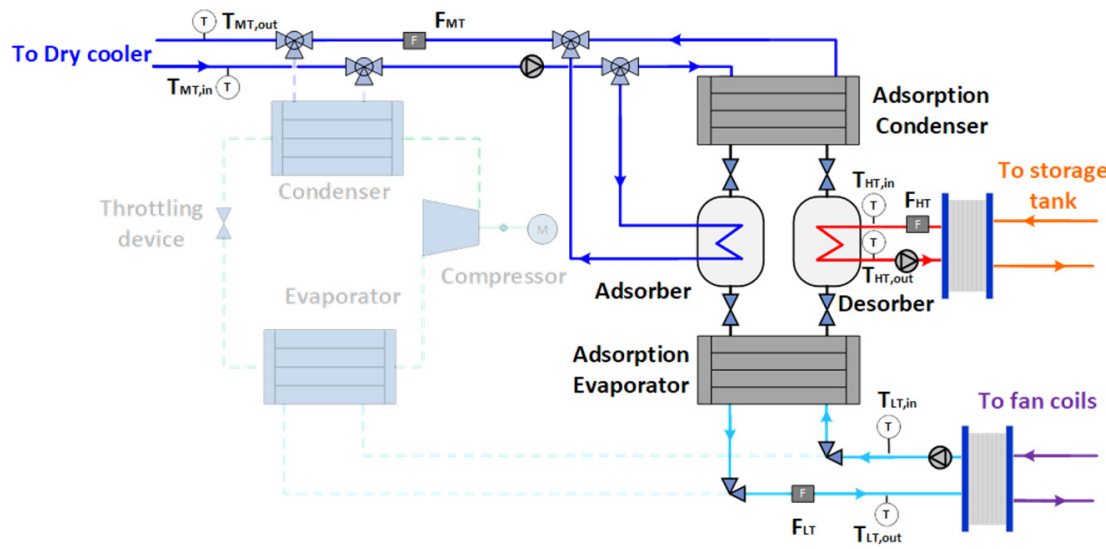

(a)

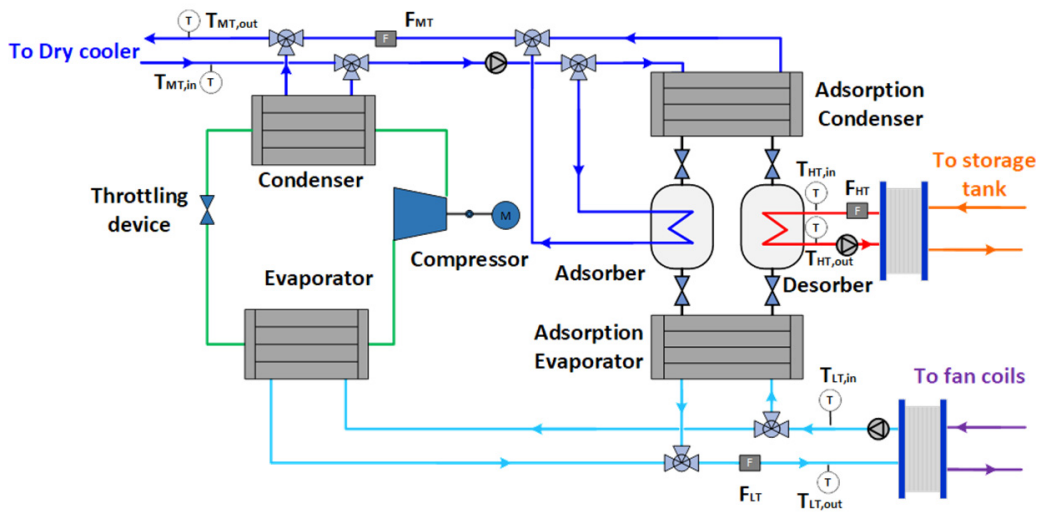

(b)

Figure 2. Detailed schematic of the hybrid adsorption chiller/backup heat pump module: (a) in adsorption only mode; (b) in combined operation. 


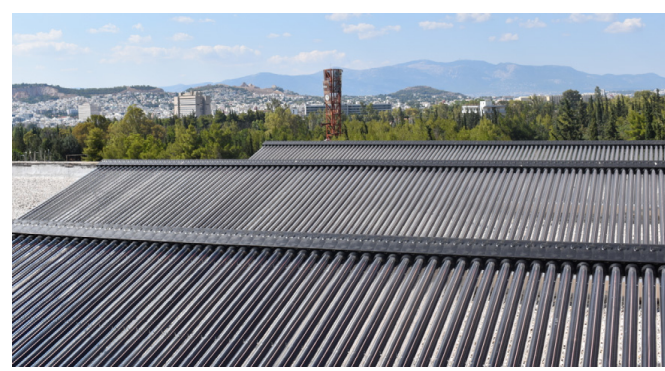

(a)

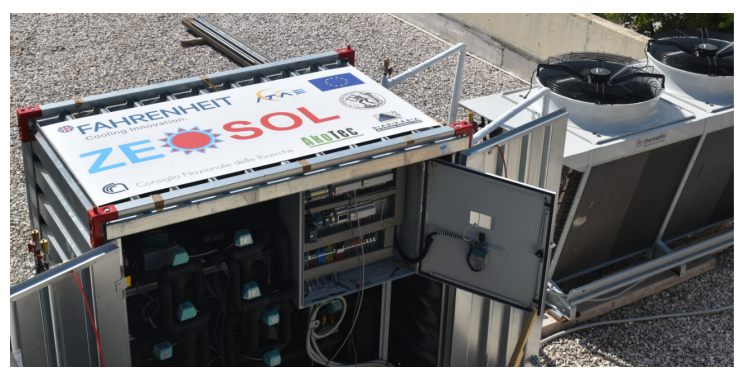

(b)
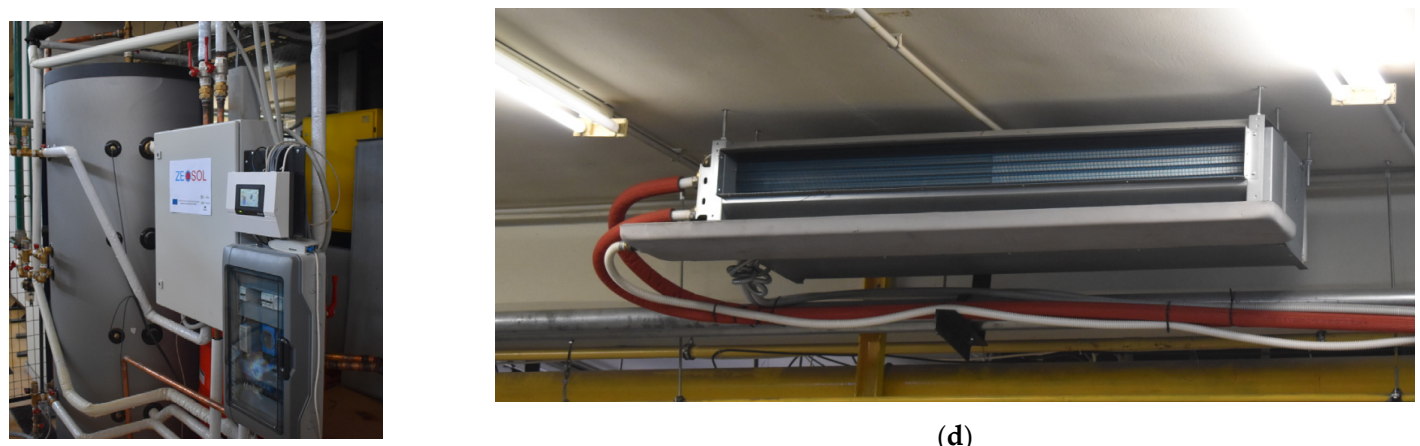

(d)

(c)

Figure 3. Overview of the experimental set-up components [35]: (a) the ETCs (Evacuated Tubes Collectors) solar field; (b) the hybrid chiller-dry cooler set-up; (c) the solar station and the storage tank and (d) the hydronic ducted fan coil unit.

\section{Experimental Measuring of Separate Components}

The preliminary measuring of the proposed system was divided into three parts: (a) the experimental assessment of the solar collectors and the storage tank, (b) the performance testing of the hybrid adsorption chiller, and (c) the dry cooler along with all the involved auxiliary equipment (e.g., circulations pumps).

The solar collectors used in the system were heat pipe evacuated tube collectors, manufactured by Akotec specifically for the ZEOSOL system, able to operate efficiently between 65 and $95{ }^{\circ} \mathrm{C}$. The collectors were tested by a certified institute according to ISO 9806. The collector efficiency, shown in Figure 4, is calculated as follows:

$$
\eta=\eta_{0}-c_{1} \frac{T_{c o l}-T_{a}}{\mathrm{G}}-c_{2} \frac{\left(T_{c o l}-T_{a}\right)^{2}}{\mathrm{G}}
$$

As the coefficients $c_{0}, c_{1}$, and $c_{2}$ are confidential, a graphical overview of the solar collector efficiency is presented in Figure 4 with respect to other commercial solar collectors. This representation was created for standard test conditions (STC), namely, an ambient temperature of $25^{\circ} \mathrm{C}$ and a solar irradiance of $1000 \mathrm{~W} / \mathrm{m}^{2}$. 


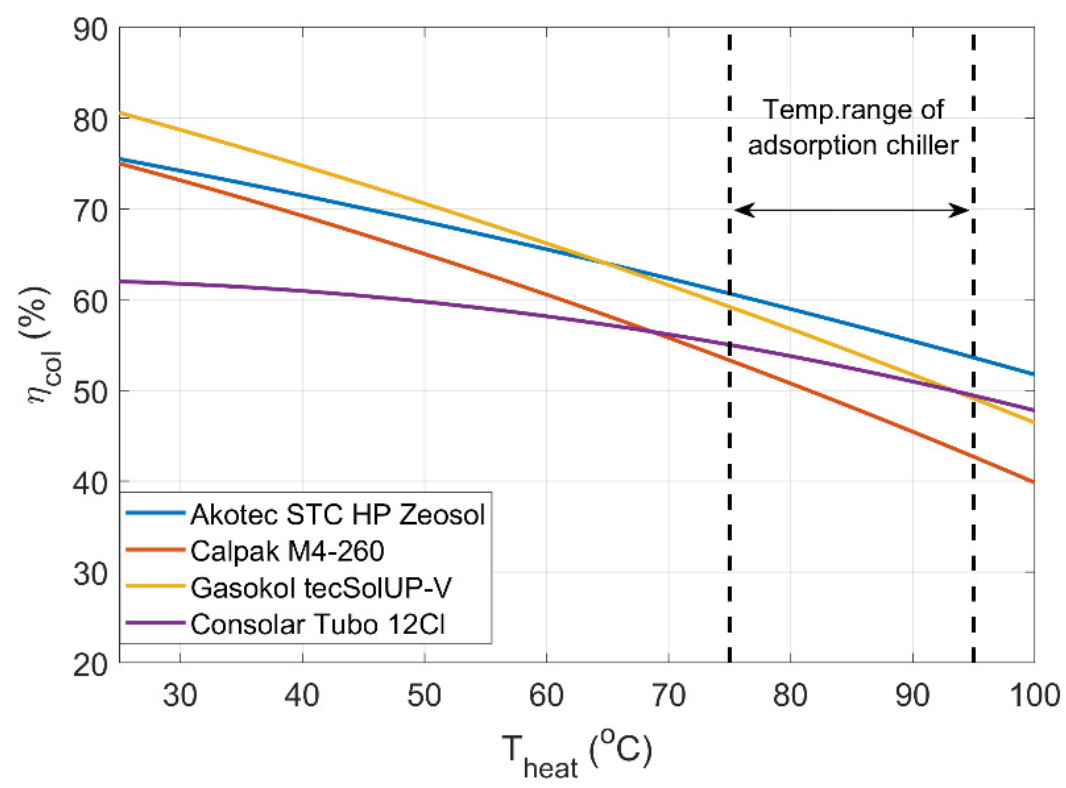

Figure 4. Performance curve of the developed solar collectors for the ZEOSOL system (blue line) in comparison to other commercial solar collectors.

On the other hand, the adsorption chiller was developed and experimentally tested by the respective manufacturers, Fahrenheit $\mathrm{GmbH}$. The performance results of the separate testing of the adsorption chiller revealed a maximum thermal COP of 0.54 , corresponding to an energy efficiency ratio (EER) as high as 45 for a driving temperature of $85^{\circ} \mathrm{C}$ [22]. The aforementioned COP for the adsorption chiller is defined by Equation (2).

$$
C O P=\frac{\dot{Q}_{L T}}{\dot{Q}_{H T}}
$$

where HT refers to the driving heat supplied to the adsorption chiller, and LT refers to the low-temperature stream which provides the cooling effect. On the other hand, the EER is defined as the ratio between the cooling capacity $\dot{Q}_{L T}$ and the total electric power consumption of the system $\dot{W}_{e l}$.

$$
E E R=\frac{\dot{Q}_{L T}}{\dot{W}_{e l}}
$$

For the determination of the total electric power consumption of the system, in addition to the electrical consumption of the dry cooler, $\dot{W}_{e l, d c}$, the following aspects also contribute: (i) the power consumption of the heat pump's compressor, $\dot{W}_{\text {el,com, }}$ and (ii) the electrical consumption for the six pumps of the system, as shown in Figure 1. The total electrical power consumption is calculated as follows:

$$
\dot{W}_{e l, t o t}=\dot{W}_{e l, c o m}+\dot{W}_{e l, d c}+\sum \dot{W}_{e l, p u m p s} .
$$

The equations for the power consumption of the HT, medium temperature (MT), and LT pumps of Figure 1 can be found in Reference [22]. Moreover, the fan coil pump is identical to the LT pump; thus, the same power consumption profile is realized. The solar collector's circuit pump, installed at the solar station of the set-up (Figure 3c) is a Grundfos pump, model UPM3 Solar 25-145. On the other hand, the storage pump is a pump from the same manufacturer, model UPS2 15-50. The electric power consumption curves, as provided by the manufacturer, of the aforementioned pumps are shown in Figure 5a. 
The backup heat pump is a custom-made module developed for this specific application, and a series of experiments were conducted at CNR-ITAE to evaluate its performance in coupling with the dry cooler of the system. Figure $5 b, c$ show that the performance of the backup heat pump, operating with R134a at a cooling water temperature of $7{ }^{\circ} \mathrm{C}$, is considered satisfactory, achieving COP values as high as 4 . On the other hand, Figure $5 \mathrm{~d}$ presents the power dissipated by the dry cooler as a function of the temperature difference between the water input and air.

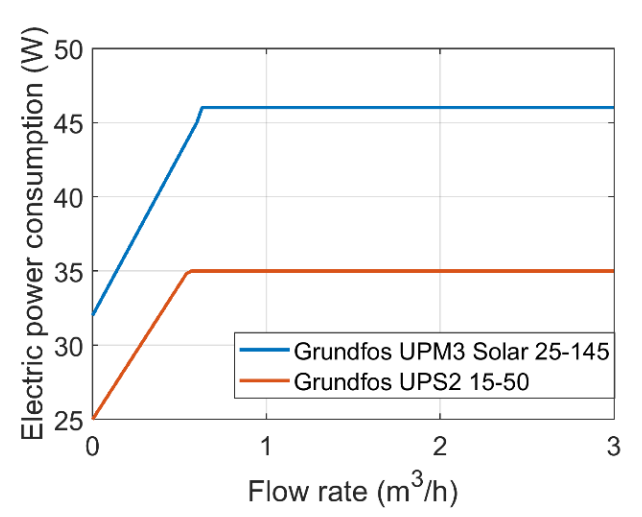

(a)

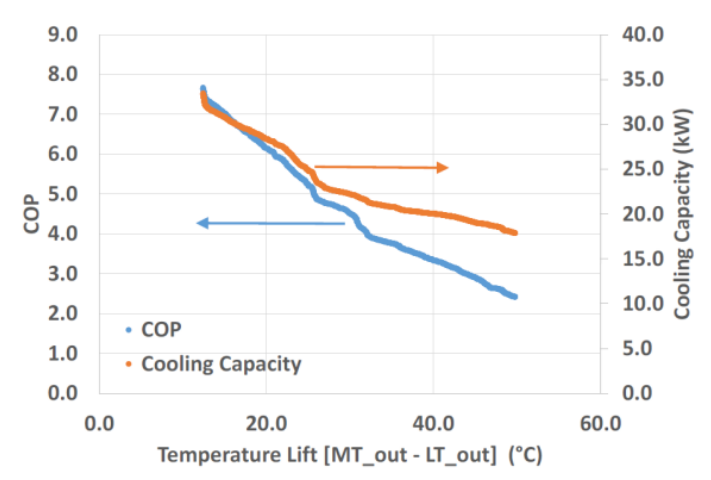

(c)

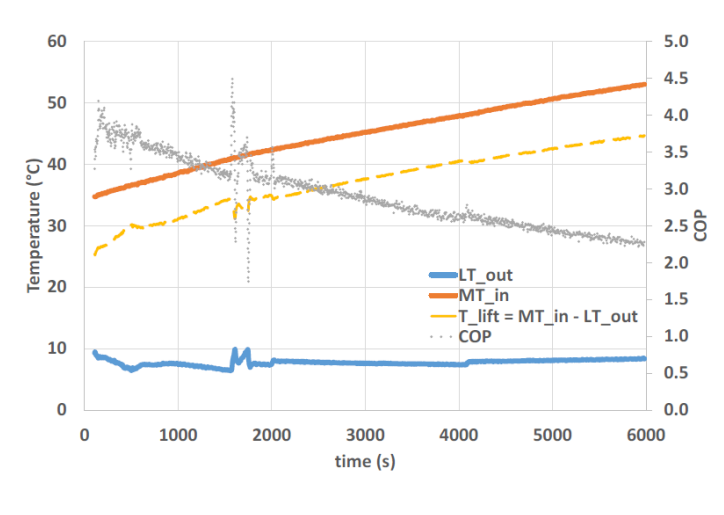

(b)

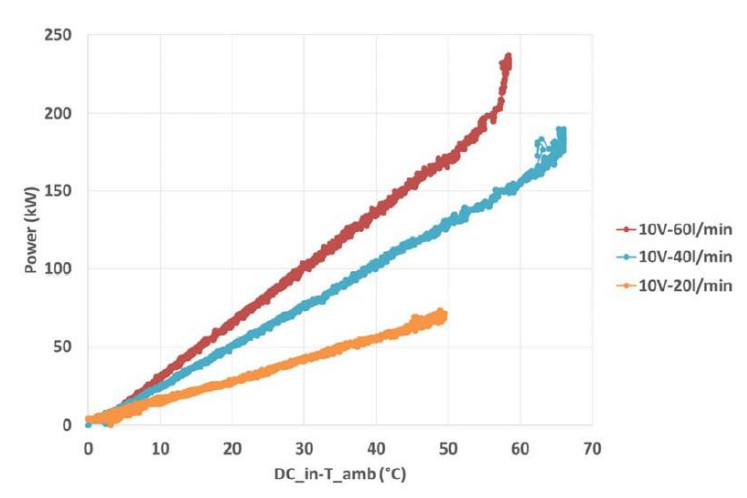

(d)

Figure 5. Experimental results of (a) the electrical consumption of the pumps, as well as the developed backup heat pump performance; (b) at maximum flow rate; (c) as a function of the maximum temperature lift and (d) cooling map of the dry cooler for variable flow rates at maximum fan speed.

Regarding the performance of the backup heat pump, its COP is defined by Equation (5).

$$
\mathrm{COP}=\frac{\dot{Q}_{L T}}{\dot{W}_{\text {el, com }}} .
$$

\section{Results of Solar Adsorption Cooling Unit Performance}

In this section, the experimental results of the developed set-up operating solely with the adsorption chiller are presented.

Figure 6 shows the temperature trend and performance measured on a typical summer day. In particular, Figure 6a presents an overview of the ambient conditions, with respect to the temperature and the solar irradiance for the week of the measurements.

As shown in Figure 6a, the solar irradiance in the evaluated week (first week of August 2019) is rather lower than the average peak values for the summer of a typical year in Athens, not exceeding $1000 \mathrm{~W} / \mathrm{m}^{2}$. On the other hand, the simultaneously higher ambient temperatures that occurred in 
the investigated days resulted in operating all the components at higher temperature levels, which decreased their efficiency. Figure $6 \mathrm{~b}, \mathrm{c}$ presents the temperature profiles for the solar collector/storage tank module and for the adsorption chiller secondary streams, respectively. The adsorption chiller was set to start its operation at $65^{\circ} \mathrm{C}$ for the HT in the stream, resulting, in combination with the available solar irradiance, in operating only a few hours per day close to the solar noon. Despite the less optimal conditions, the system was able to cool down the water to $7.5^{\circ} \mathrm{C}$, which was the setpoint for the low-temperature circuit, even though the driving temperature was less than $80^{\circ} \mathrm{C}$ in all cases, although at the expense of lower overall performance. The profiles of Figure $6 \mathrm{c}$ outline the necessity for a modification of the control strategy for the involved circulating pumps such that higher driving temperatures are obtained, ensuring maximum efficiency of the chiller. At this point, it has to be highlighted that Figure 6 refers to adsorption only mode; thus, in the absence of driving solar heat, the system is off, which results in no operation at night.

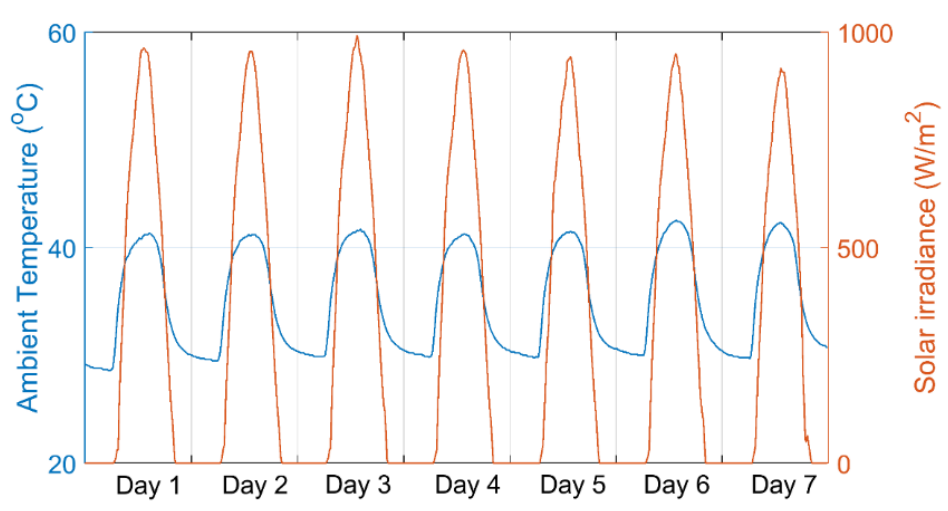

(a)

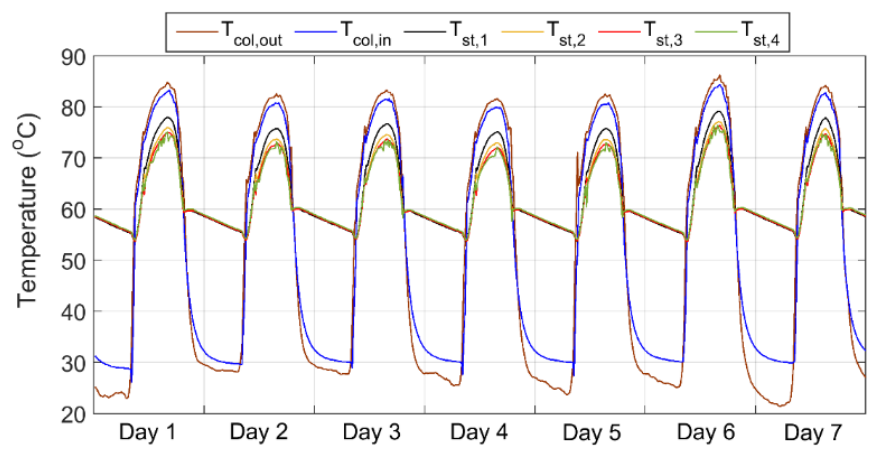

(b)

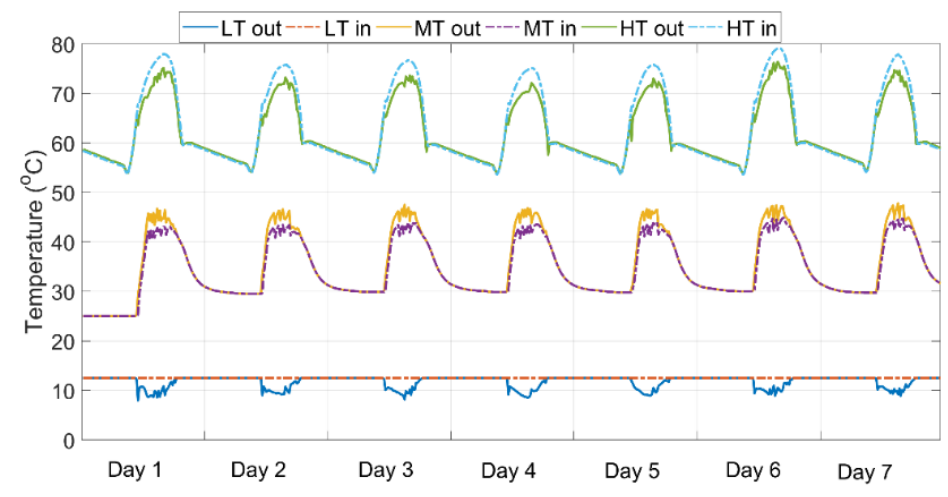

(c)

Figure 6. (a) Ambient conditions at the period of the experiments; (b) experimental results with respect to the solar sub-circuit temperatures and (c) with respect to the chiller's secondary stream temperatures. 
Figure 7 presents the performance results for the entire ZEOSOL system, in adsorption-only mode, based on the definitions of Equations (2) and (3) on a typical summer day. Figure 7a shows the cooling power production of the chiller during the investigated week and the total electrical power consumption, as defined by Equation (4). As shown in Figure 7a, the maximum obtained cooling power output was around $5 \mathrm{~kW}$, which was approximately $40 \%$ of the nominal chiller's cooling capacity, mainly attributed to the lower driving temperatures during the period of the measurements. On the other hand, the electrical power consumption was significantly low, with a maximum of $900 \mathrm{~W}$, mainly due to the operation of the dry cooler, which accounted for more than $60 \%$ of the total power consumption of the system. The corresponding performance indicators are presented in Figure $7 \mathrm{~b}$. The maximum obtained thermal COP was approximately 0.535 , for a maximum reported driving temperature of $79^{\circ} \mathrm{C}$, while the corresponding maximum EER was as high as 12, with an average operation at approximately 5.8. Similarly to Figure 6, both the cooling production and the EER of the system highlight the necessity for further optimization of the system's control and operational strategy to maximize cooling output at a reduced specific power consumption.

$$
\text { a) }
$$

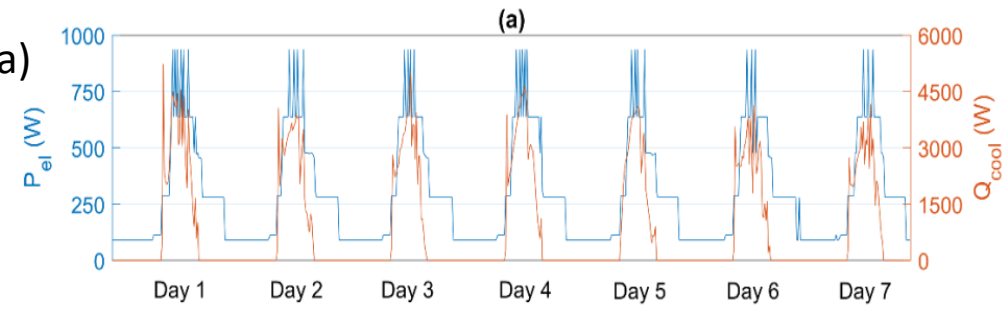

b)

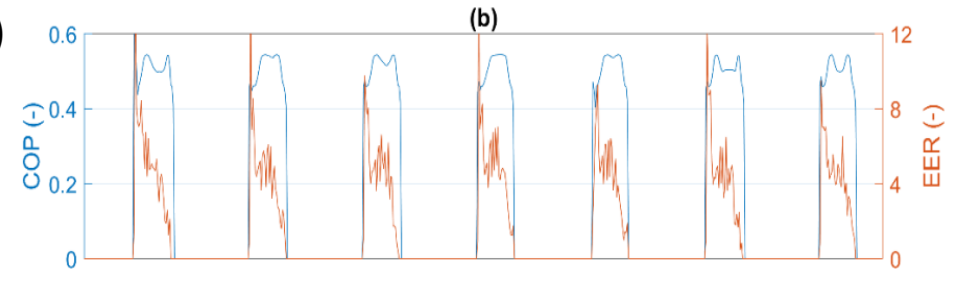

Figure 7. Performance results of proposed system prototype with respect to (a) the produced cooling output and the respective electrical consumption and $(\mathbf{b})$ the corresponding coefficient of performance $(\mathrm{COP})$ and energy efficiency ratio (EER) values.

Figures 8-10 present, instead, the performance results for the ZEOSOL system, during a hot summer week and on cloudy days (September).

As shown in Figure 8a, the solar field is capable of providing hot water at a good thermal level when the solar radiation ranges between 800 and $1000 \mathrm{~W} / \mathrm{m}^{2}$, while the pump of the solar loop continuously switches off and on to preserve water stratification in the storage tank on cloudy days or when the solar radiation drops below $800 \mathrm{~W} / \mathrm{m}^{2}$ (Figure $8 b$ ).

As shown in Figure 9, the adsorption chiller can produce cold water at $15{ }^{\circ} \mathrm{C}$ and release the process heat at $25-30{ }^{\circ} \mathrm{C}$, both on a hot day and on a cloudy day; however, cold production is not continuous with a lower solar radiation, thus demonstrating the need for the operation of the electrical backup unit, not only to cover the remaining loads but also to allow for sufficient re-charging of the storage tank for more efficient operation of the adsorption module upon resumption of its operation.

Finally, as depicted in Figure 10, the maximum obtained cooling power output was around $6 \mathrm{~kW}$ on a hot day, while it ranged between 2 and $5 \mathrm{~kW}$ when it was cloudy, due to the lower driving temperatures. During the same measurements, the electrical power consumption was significantly low, ranging between 50 (electronic consumption) and $900 \mathrm{~W}$ (operation of the fans the dry cooler), while the maximum obtained thermal COP was approximately 0.53 for a driving temperature of $80^{\circ} \mathrm{C}$, with the corresponding average EER of 7. 

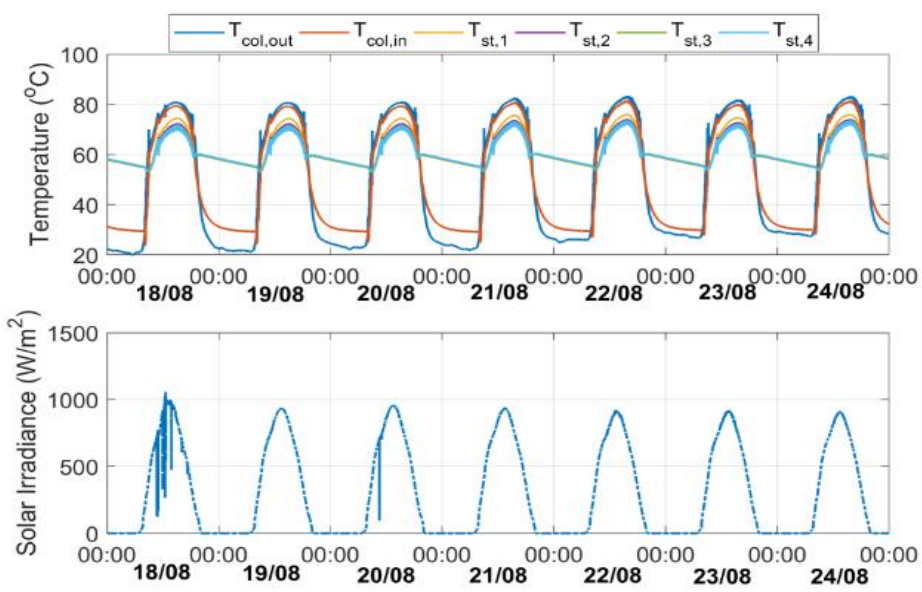

(a)
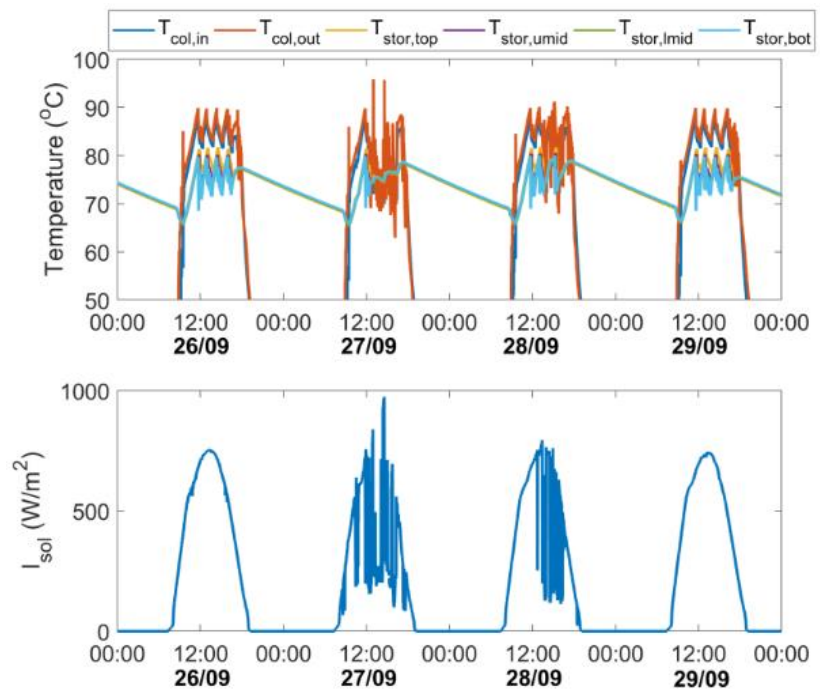

(b)

Figure 8. ZEOSOL system behavior on hot summer days (a) and on cloudy days (b).

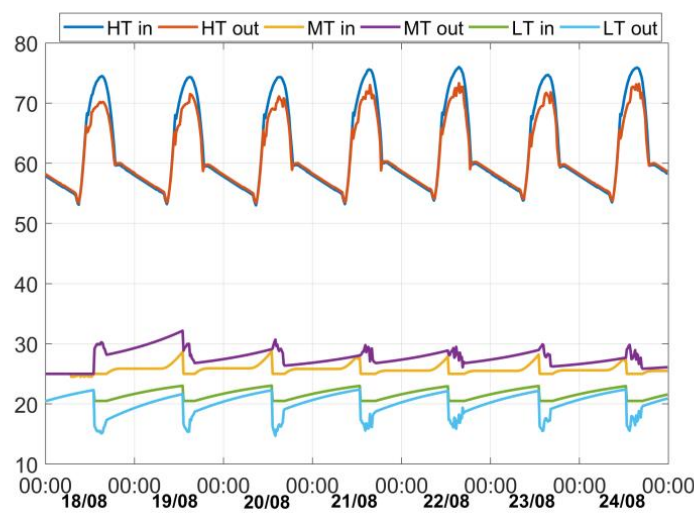

(a)

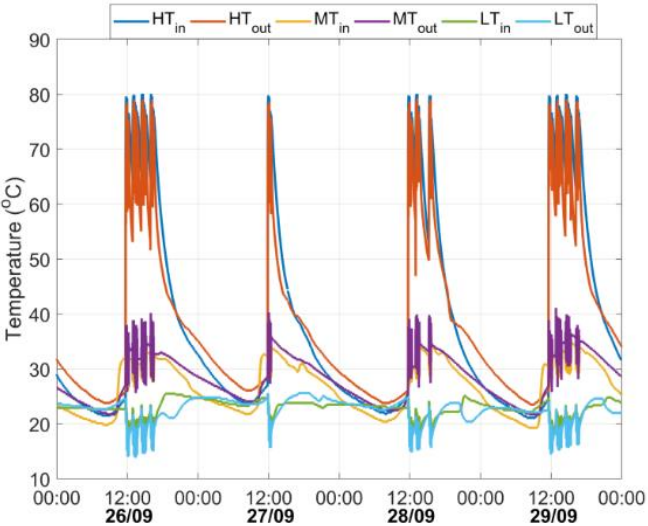

(b)

Figure 9. Temperature of secondary chiller's streams on (a) hot summer days and (b) cloudy days. 


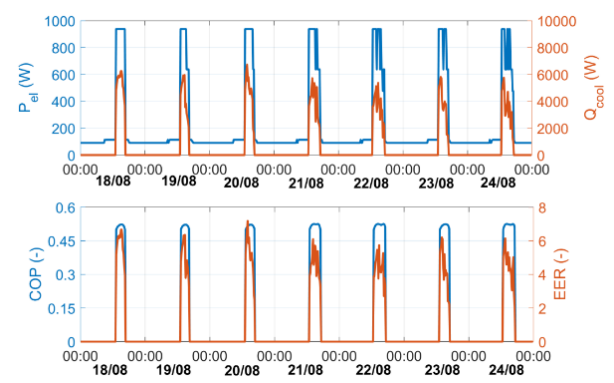

(a)
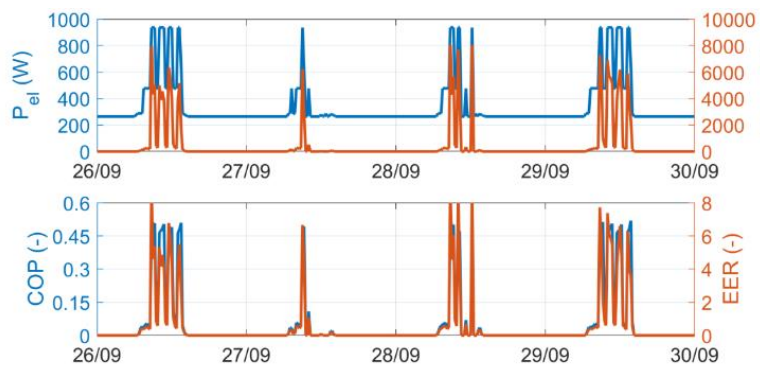

(b)

Figure 10. Performance results of proposed system prototype: the produced cooling output, the respective electrical consumption, and the corresponding COP and EER values (a) on hot summer days and (b) on cloudy days.

\section{Results of Combined Operation}

In the following figures, a combined operation scheme was investigated. In general, the weight of the experiments was highly shifted toward the adsorption-only operation, as it was the main module to be combined with the solar field, while the operation of the backup heat pump was already investigated and lacked significant scientific interest. The interest of this experiment was, therefore, shifted toward using the backup heat pump to cool down the water prior to the startup of the adsorption chiller (in the morning when the HT setpoint was not yet reached) in order to allow for more optimal conditions for the operation of the adsorption chiller and, thus, higher efficiencies.

As shown in Figure 11a, the temperature profiles in the storage tank and the solar field were much more stable, following the less sharp increases in the heat demands by the adsorption chiller. The spikes in the MT and LT, shown in Figure 11b, are due to the transition from the adsorption part to the on/off operation of the backup heat pump. This behavior, however, would not affect the end user, since oscillations in the LT circuit were small and around the LT setpoint of $15^{\circ} \mathrm{C}$. With respect to the system's performance (Figure 12), the combined operation enhanced the overall performance, achieving close to nominal cooling output, with a maximum EER of 11.5 in the combined operation, corresponding to an adsorption chiller COP of approximately 0.525 .
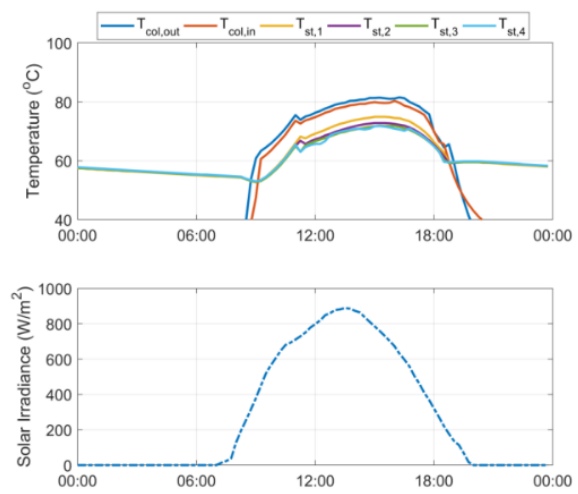

(a)

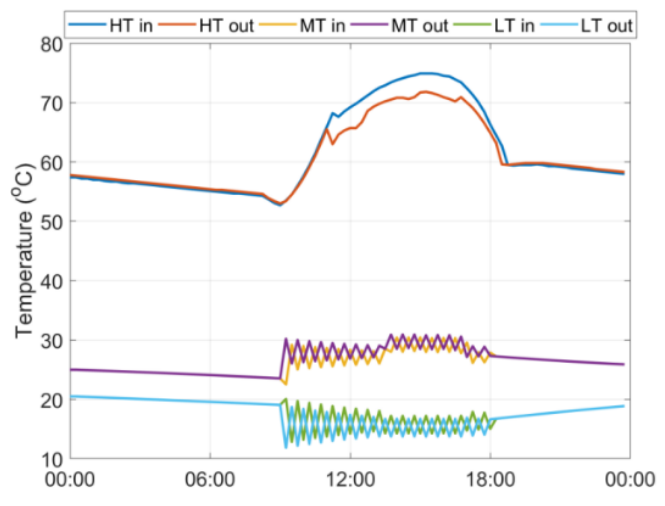

(b)

Figure 11. Overview of (a) the solar field temperatures and solar irradiance and (b) the adsorption chiller for combined operation. 

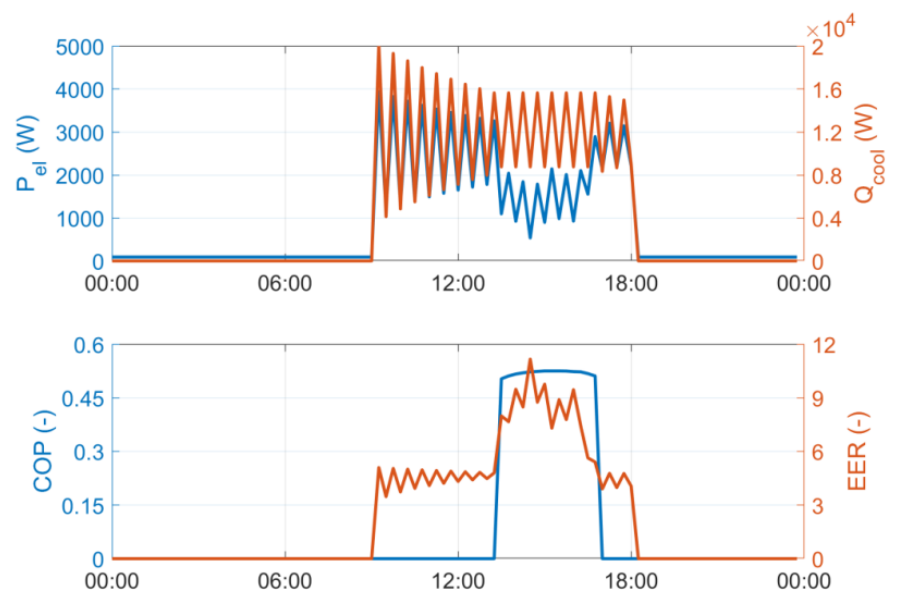

Figure 12. Overview of the cooling/electrical loads and the system's performance for combined operation.

\section{Economic Evaluation of Solar Adsorption Cooling Unit}

Using the performance results of the previous section, an economic analysis was conducted to evaluate the economic viability of the ZEOSOL system for a number of countries in comparison to other commercially available technologies for cooling and heating. For this purpose, a 500- $\mathrm{m}^{2}$ reference multi-family building was considered. As the reference heating system of the building, a $30-\mathrm{kW}$ condensing gas boiler was considered, while, for the cooling loads, single split air-conditioning units were considered with a total cooling capacity of $24 \mathrm{~kW}$. Apart from the ZEOSOL system, the other evaluated technologies were as follows:

- A boiler for the heating loads of the building and a solar cooling system for the cooling loads.

- A reversible heat pump powered by the grid.

- A reversible heat pump powered by a photovoltaic panel field of $10 \mathrm{kWp}$ capacity.

The investigated locations were Berlin (Germany), Paris (France), Vienna (Austria), Rome (Italy), Athens (Greece), Larnaca (Cyprus), Madrid (Spain), Lisbon (Portugal), and Istanbul (Turkey). The estimation of the annual heating/cooling loads was conducted using data from the literature. More specifically, the building envelope's characteristics, as well as the heating system per country, were derived from the TABULA webtool [36], considering in all cases the most modern typology. Given that the aforementioned database does not provide data for the cooling system, in all cases, single-split air conditioning units of seasonal energy efficiency ratio (SEER) equal to 6.95 were considered. In order to allow the comparison on an equal basis, in all cases, the total building surface was considered equal to $500 \mathrm{~m}^{2}$, as mentioned before. The energy simulations for all buildings were eventually conducted using EnergyPlus software [37], and the results are summarized in Figure 13a. With respect to other assumptions, required for the simulations in EnergyPlus, the air leakage was set to eight air changes per hour, while the natural ventilation was set to year-round three days per week. Regarding the temperature set points, we set $20^{\circ} \mathrm{C}$ for heating, while the respective value for cooling mode was equal to $25^{\circ} \mathrm{C}$; the operating schedule was in both modes between 4:00 p.m. and 8:00 a.m. With respect to the estimation of the capital costs per system, the following assumptions were considered:

- The ZEOSOL system has a specific capital cost of $2 \mathrm{k} € / \mathrm{kWc}$, while the installation costs were considered equal to $1 \mathrm{k} €$.

- For the reference system, the cost of the boiler was considered equal to $2.8 \mathrm{k} €$, and the total cost for the single split air-conditioning units was considered equal to $7.3 \mathrm{k} €$, based on commercial prices from the Greek heating, ventilation, and air-conditioning (HVAC) market.

- For the solar cooling system, a specific cost of $3 \mathrm{k} € / \mathrm{kWc}$ was considered with installation costs of $2 \mathrm{k} €$. 
- The reversible heat pump cost was considered to be equal to $11.2 \mathrm{k} €$, and the specific costs of the PVs were considered equal to $1.1 \mathrm{k} / \mathrm{kWp}$ [38].

- For simplification, all scenarios considered a maintenance cost of $400 € /$ year, apart from the reference case which was estimated to have $200 € /$ year.

Based on the above, the capital costs per system were estimated as listed in Figure 11b. As shown, the costs of all systems were comparable, apart from the case of the boiler with solar cooling, which had a capital cost exceeding $35 \mathrm{k} €$.

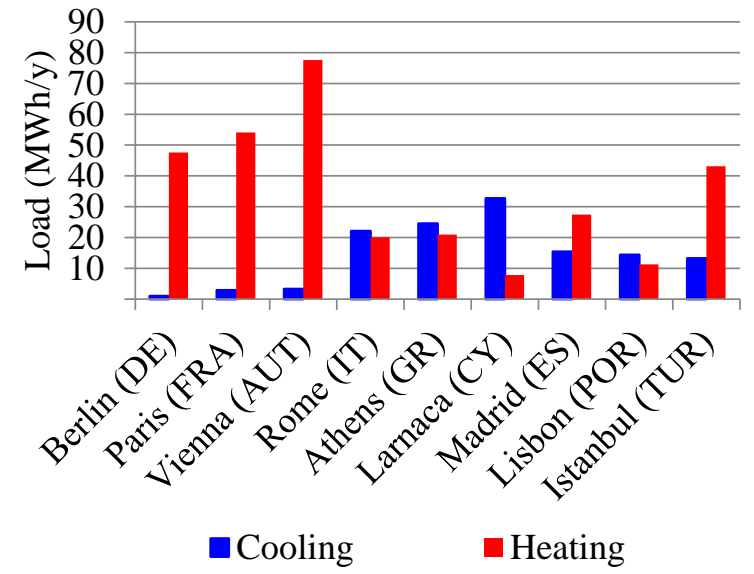

(a)

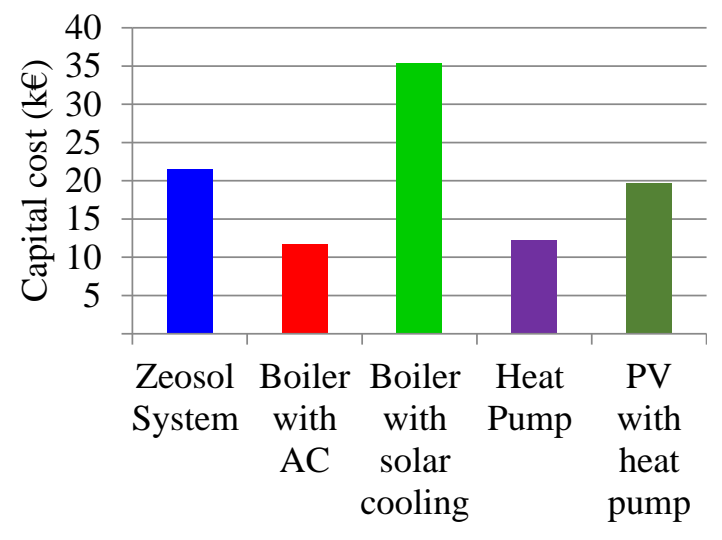

(b)

Figure 13. (a) Cooling/heating loads for the considered building in the investigated regions and (b) capital costs for the considered systems.

The economic performance for the different scenarios was estimated on the basis of considering, as a profit from each alternative system, the avoided annual costs of the reference system (maintenance and operation) reduced by the respective costs of the selected per case system. The index that was used for this analysis was the payback period $(P b P)$.

$$
P b P_{\text {system }, i}=\frac{(\text { Capital cost })+(\text { installation })}{(\text { annual cost of reference })-(\text { annual cost of system }, i)} .
$$

For the estimation of the operational costs, the recent prices for electricity were considered based on data from Eurostat for the first semester of 2019 [39]. The results of the analysis are presented in Figure 14. As shown, the ZEOSOL system's performance was more favorable than the scenarios of a boiler with solar cooling and a grid-connected heat pump. In terms of the comparison with a PV-driven heat pump, the ZEOSOL system was favorable in countries with dominant heating loads and lower solar irradiance during the heating period. This is because the custom-made backup heat pump of the ZEOSOL system has a higher efficiency than commercial reversible heat pumps, an effect which is further enhanced by the boost of the sorption chiller when there is solar energy available. In fact, the lowest payback periods were reported for Paris and Vienna, with 7.9 and 7.2 years, respectively.

The economic performance of ZEOSOL was also considered quire competitive in regions with higher cooling demands, with payback periods of 11.3 years for Rome and 11.9 years for Madrid, respectively. However, the PV/heat pump system had a better performance in such regions overall. This is mainly justified by the high COPs of the heat pump at the period of maximum production of the PVs, which results in almost zero grid-dependent operation. On the contrary, the ZEOSOL system uses its backup heat pump to cover peak loads, thus resulting in electrical consumption and eventually smaller profits. At this point, it has to be mentioned that the analysis did not evaluate the use of any system for domestic hot water (DHW), which could significantly vary the outcomes. 


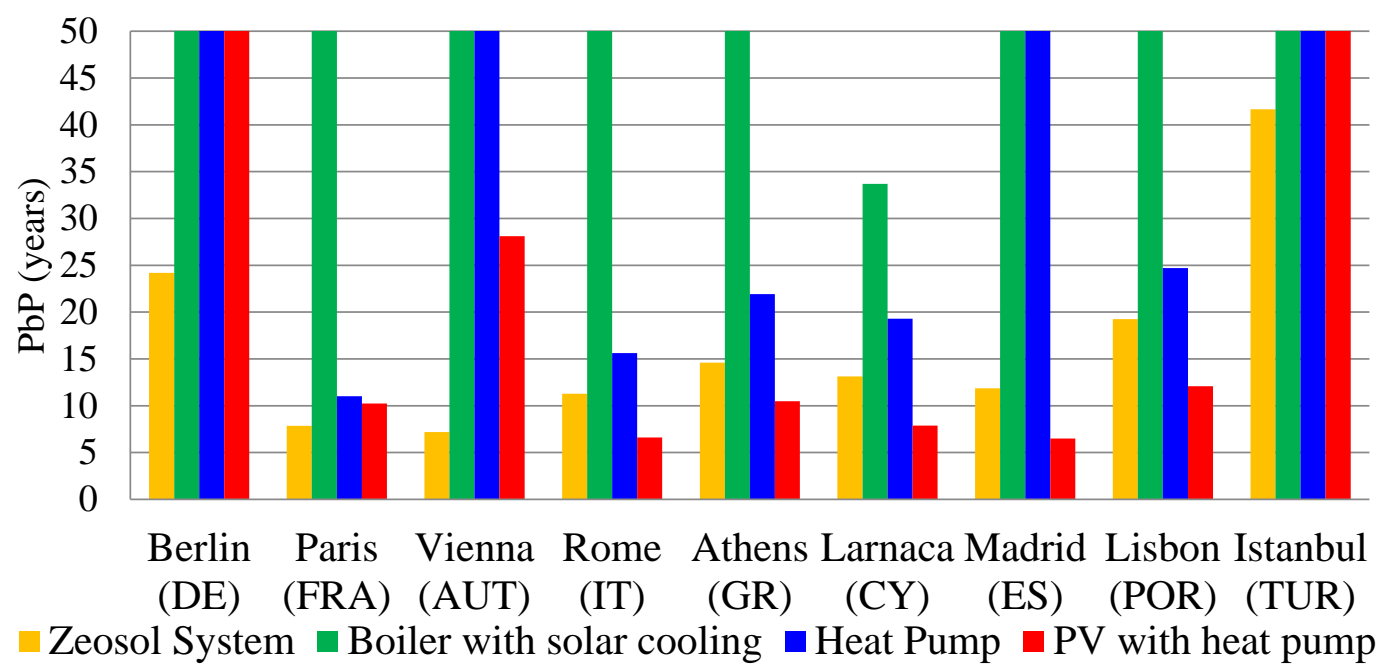

Figure 14. Economic performance of considered technologies for the investigated countries.

\section{Conclusions}

In this study, the preliminary performance results of a solar-driven hybrid adsorption chiller coupled with a backup heat pump were presented. The experimental analysis of the solar-driven adsorption chiller revealed that the system, despite non-optimal conditions (smaller solar irradiance, high ambient temperatures), operated at a satisfactory level, with a maximum COP of 0.535 . The developed system was proven to significantly decrease the electrical power consumption, achieving a maximum EER of 5.83 (with more than $60 \%$ of the total consumption coming from the system's dry cooler). These results are considered optimistic for the upcoming phases of the experimental evaluation of the system, not only for cooling mode operation but also for heating mode operation. However, as the experimental testing is in a preliminary phase, there cannot be objective conclusions toward the system's performance, especially prior to the evaluation of the combined adsorption chiller/backup heat pump operation, which allows for even higher EER values under an optimized operational strategy. Using the combined operation, the system is expected to fully cover the loads of a $12.5-\mathrm{kW}$-peak building, with an optimum solar fraction of around $60 \%$, depending on the climatic conditions of the site of installation. An alternative to further enhance the solar fraction of the system would be the addition of photovoltaic (PV) panels; however, this option was not evaluated within the framework of this project as it would increase the capital costs and add further complexity to the system. Regarding the economic aspects of this technology, the investigated system has a better economic performance in regions with dominant heating loads, with payback periods as low as 7.2 years for Vienna, Austria. On the other hand, for the countries of the Mediterranean region, the system is outperformed by $\mathrm{PV} /$ heat pump systems due to the high maturity of the latter.

Author Contributions: T.C.R. and G.K. developed the model that was used and contributed in writing the original draft. T.C.R. conducted the experimental validation of the results and also contributed in the writing of the review and editing of the manuscript. S.V. and A.S. conducted the experimental characterization of the system components at CNR-ITAE. S.V. supervised the preparation of the manuscript and contributed in the writing, editing and reviewing the text. U.W. and M.T. developed the back-up unit at Fahrenheit and contributed in writing the manuscript. N.H. and U.S. conducted the experimental activity on the solar collectors at Akotec. S.K. supervised the preparation of the manuscript and was the project coordinator. All authors have read and agreed to the published version of the manuscript.

Funding: The analysis was conducted as a part of the ZEOSOL project funded by the European Union's Horizon 2020 research and innovation program under grant agreement No. 760210. This scientific paper was supported by the Onassis Foundation, Scholarship ID: G ZO 025-1/2018-2019.

Conflicts of Interest: The authors declare no conflicts of interest. 


\section{Nomenclature}

$\begin{array}{ll}\text { A } & \text { Aperture area, } \mathrm{m}^{2} \\ \mathrm{c}_{1} & \text { Heat loss coefficient } \mathrm{W} /\left(\mathrm{m}^{2} \cdot \mathrm{K}\right) \\ \mathrm{c}_{2} & \text { Heat loss coefficient } \mathrm{W} /\left(\mathrm{m}^{2} \cdot \mathrm{K}^{2}\right) \\ \mathrm{G} & \text { Solar radiation, } \mathrm{W} / \mathrm{m}^{2} \\ \eta & \text { Efficiency } \\ \eta_{0} & \text { Collector efficiency, adm } \\ \mathrm{PbP} & \text { Payback period, years } \\ \dot{Q} & \text { Heating/cooling capacity, } \mathrm{kW} \\ T & \text { Temperature, }{ }^{\circ} \mathrm{C} \\ \dot{W} & \text { Power, } \mathrm{kW}\end{array}$

\section{Subscripts}

$\begin{array}{ll}\text { a } & \text { Ambient } \\ \text { col } & \text { Collector } \\ \text { com } & \text { Compression } \\ \text { el } & \text { Electrical } \\ \text { dc } & \text { Dry cooler } \\ \text { pumps } & \text { Pumps }\end{array}$

\section{Abbreviations}

$\begin{array}{ll}\text { COP } & \text { Coefficient of performance } \\ \text { EER } & \text { Energy efficiency ratio } \\ \text { HT } & \text { High temperature } \\ \text { LT } & \text { Low temperature } \\ \text { MT } & \text { Medium temperature }\end{array}$

\section{References}

1. EUR-Lex-32018L2001-EN—EUR-Lex (n.d.). Available online: https:/eur-lex.europa.eu/eli/dir/2018/2001/oj (accessed on 13 March 2020).

2. Karellas, S.; Roumpedakis, T.C.; Tzouganatos, N.; Braimakis, K. Solar Cooling Technologies; CRC Press: Boca Raton, FL, USA, 2018.

3. Buonomano, A.; Calise, F.; Palombo, A. Solar heating and cooling systems by absorption and adsorption chillers driven by stationary and concentrating photovoltaic/thermal solar collectors: Modelling and simulation. Renew. Sustain. Energy Rev. 2018, 82, 1874-1908. [CrossRef]

4. Sarbu, I.; Sebarchievici, C. Review of solar refrigeration and cooling systems. Energy Build. 2013, 67, 286-297. [CrossRef]

5. IEA Webstore. Technology Roadmap-Solar Photovoltaic Energy 2014 (n.d.). Available online: https: //webstore.iea.org/technology-roadmap-solar-photovoltaic-energy-2014 (accessed on 11 February 2020).

6. Eicker, U.; Pietruschka, D.; Haag, M.; Schmitt, A. Energy and economic performance of solar cooling systems worldwide. In Energy Procedia; Elsevier Ltd.: Amsterdam, The Netherlands, 2014; pp. 2581-2589. [CrossRef]

7. Ferreira, C.I.; Kim, D.S. Techno-economic review of solar cooling technologies based on location-specific data. Int. J. Refrig. 2014, 39, 23-37. [CrossRef]

8. Freni, A.; Maggio, G.; Vasta, S.; Santori, G.; Polonara, F.; Restuccia, G. Optimization of a solar-powered adsorptive ice-maker by a mathematical method. Sol. Energy 2008, 82, 965-976. [CrossRef]

9. Bellos, E.; Tzivanidis, C.; Antonopoulos, K.A. Exergetic, energetic and financial evaluation of a solar driven absorption cooling system with various collector types. Appl. Therm. Eng. 2016, 102, 749-759. [CrossRef]

10. Drosou, V.N.; Tsekouras, P.D.; Oikonomou, T.I.; Kosmopoulos, P.I.; Karytsas, C.S. The HIGH-COMBI project: High solar fraction heating and cooling systems with combination of innovative components and methods. Renew. Sustain. Energy Rev. 2014, 29, 463-472. [CrossRef] 
11. Drosou, V.; Kosmopoulos, P.; Papadopoulos, A. Solar cooling system using concentrating collectors for office buildings: A case study for Greece. Renew. Energy 2016, 97, 697-708. [CrossRef]

12. Roumpedakis, T.C.; Christou, T.; Monokrousou, E.; Braimakis, K.; Karellas, S. Integrated ORC-Adsorption cycle: A first and second law analysis of potential configurations. Energy 2019, 179, 46-58. [CrossRef]

13. Wang, L.W.; Wang, R.Z.; Oliveira, R.G. A review on adsorption working pairs for refrigeration. Renew. Sustain. Energy Rev. 2009, 13, 518-534. [CrossRef]

14. Otanicar, T.; Taylor, R.A.; Phelan, P.E. Prospects for solar cooling-An economic and environmental assessment. Sol. Energy 2012, 86, 1287-1299. [CrossRef]

15. Wang, R.Z.; Oliveira, R.G. Adsorption refrigeration-An efficient way to make good use of waste heat and solar energy. Prog. Energy Combust. Sci. 2006, 32, 424-458. [CrossRef]

16. Calise, F.; d'Accadia, M.D.; Figaj, R.D.; Vanoli, L. A novel solar-assisted heat pump driven by photovoltaic/thermal collectors: Dynamic simulation and thermoeconomic optimization. Energy 2016, 95, 346-366. [CrossRef]

17. Lu, Z.; Wang, R. Experimental and simulation analysis of low temperature heat sources driven adsorption air conditioning, refrigeration, integrating ammonia, and organic expanding power generation. Int. J. Energy Res. 2018, 42, 4157-4169. [CrossRef]

18. Rahman, A.; Ueda, Y.; Akisawa, A.; Miyazaki, T.; Saha, B. Design and Performance of an Innovative Four-Bed, Three-Stage Adsorption Cycle. Energies 2013, 6, 1365-1384. [CrossRef]

19. Habib, K.; Choudhury, B.; Chatterjee, P.K.; Saha, B.B. Study on a solar heat driven dual-mode adsorption chiller. Energy 2013, 63, 133-141. [CrossRef]

20. Lemmini, F.; Errougani, A. Experimentation of a solar adsorption refrigerator in Morocco. Renew. Energy 2007, 32, 2629-2641. [CrossRef]

21. Aristov, Y.I.; Chalaev, D.M.; Dawoud, B.; Heifets, L.I.; Popel, O.S.; Restuccia, G. Simulation and design of a solar driven thermochemical refrigerator using new chemisorbents. Chem. Eng. J. 2007, 134, 58-65. [CrossRef]

22. Chorowski, M.; Pyrka, P.; Rogala, Z.; Czupryński, P. Experimental Study of Performance Improvement of 3-Bed and 2-Evaporator Adsorption Chiller by Control Optimization. Energies 2019, 12, 3943. [CrossRef]

23. Kalkan, N.; Young, E.A.; Celiktas, A. Solar thermal air conditioning technology reducing the footprint of solar thermal air conditioning. Renew. Sustain. Energy Rev. 2012, 16, 6352-6383. [CrossRef]

24. Lu, Z.S.; Wang, R.Z.; Xia, Z.Z.; Wu, Q.B.; Sun, Y.M.; Chen, Z.Y. An analysis of the performance of a novel solar silica gel-water adsorption air conditioning. Appl. Therm. Eng. 2011, 37, 3636-3642. [CrossRef]

25. Koronaki, I.P.; Papoutsis, E.G.; Papaefthimiou, V.D. Thermodynamic modeling and exergy analysis of a solar adsorption cooling system with cooling tower in Mediterranean conditions. Appl. Therm. Eng. 2016, 99, 1027-1038. [CrossRef]

26. Alahmer, A.; Wang, X.; Alam, K.C.A. Dynamic and Economic Investigation of a Solar Thermal-Driven Two-Bed Adsorption Chiller under Perth Climatic Conditions. Energies 2020, 13, 1005. [CrossRef]

27. Wang, R.; Wang, L.; Wu, J. Adsorption Refrigeration Technology: Theory and Application; Jon Wiley \& Sons: Hoboken, NJ, USA, 2014.

28. Vasta, S.; Palomba, V.; la Rosa, D.; Mittelbach, W. Adsorption-compression cascade cycles: An experimental study. Energy Convers. Manag. 2018, 156, 365-375. [CrossRef]

29. Palomba, V.; Wittstadt, U.; Bonanno, A.; Tanne, M.; Harborth, N.; Vasta, S. Components and design guidelines for solar cooling systems: The experience of ZEOSOL. Renew. Energy 2019, 141, 678-692. [CrossRef]

30. Cyklis, P. Two stage ecological hybrid sorption-compression refrigeration cycle. Int. J. Refrig. 2014, 48, 121-131. [CrossRef]

31. Miyazaki, T.; Saha, B.B.; Koyama, S. Analytical Model of a Combined Adsorption Cooling and Mechanical Vapor Compression Refrigeration System. Heat Transf. Eng. 2017, 38, 423-430. [CrossRef]

32. Palomba, V.; Dino, G.E.; Frazzica, A. Coupling Sorption and Compression Chillers in Hybrid Cascade Layout for Efficient Exploitation of Renewables: Sizing, Design and Optimization. Renew. Energy 2020, 154, 11-28. [CrossRef]

33. About ZEOSOL-Zeosol (n.d.). Available online: http://zeosol.eu/ (accessed on 15 March 2020).

34. Palomba, V.; Varvagiannis, E.; Karellas, S.; Frazzica, A. Hybrid Adsorption-Compression Systems for Air Conditioning in Efficient Buildings: Design through Validated Dynamic Models. Energies 2019, 12, 1161. [CrossRef] 
35. Roumpedakis, T.C.; Kallis, G.; Magiri-Skouloudi, D.; Grimekis, D.; Karellas, S. Life cycle analysis of ZEOSOL solar cooling and heating system. Renew. Energy 2020, 154, 82-98. [CrossRef]

36. TABULA WebTool (n.d.). Available online: http://webtool.building-typology.eu/\#bm (accessed on 22 February 2020).

37. University of California through the Ernest Orlando Lawrence Berkeley National Laboratory, Oak Ridge National Laboratory, managed by Ut-Battelle, Alliance For Sustainable Energy, LLC, and other contributors. The, EnergyPlus ${ }^{\mathrm{TM}}$ Version 8.8.0 Documentation-Engineering Reference. Available online: https: //energyplus.net/sites/all/modules/custom/nrel_custom/pdfs/pdfs_v8.8.0/EngineeringReference.pdf (accessed on 31 December 2019).

38. Jaeger-Waldau, A. PV Status Report 2018; Publications Office of the European Union: Luxembourg, 2018. [CrossRef]

39. EUROSTAT-Electricity Price Statistics—Statistics Explained. 2019. Available online: https://ec.europa.eu/ eurostat/statistics-explained/index.php/Electricity_price_statistics (accessed on 22 February 2020).

(C) 2020 by the authors. Licensee MDPI, Basel, Switzerland. This article is an open access article distributed under the terms and conditions of the Creative Commons Attribution (CC BY) license (http://creativecommons.org/licenses/by/4.0/). 